\title{
EDITORIAL: SAME OLD?
}

\author{
Christopher Fox
}

In the last chapter of The Rest is Noise, Alex Ross muses on the changing status of composers within society. He recalls how 'on Mahler's last day on earth, the Viennese press reported that his body temperature was wavering between 37.2 and 38 degrees Celsius'. But today 'composers have largely vanished from the radar screen of mainstream culture' and as John Adams walks down the street to his next rehearsal 'no one whispers "Der Adams!" Ross is probably right. Not only do composers no longer command popular attention, they don't command all that much specialist attention either. When Adams walks down Silk Street to rehearse at the Barbican for the 'Reich, Glass, Adams: the Sounds that Changed America' festival in December, how many Guildhall students will even recognise him?

Yet Adams is really quite famous. Certainly he is far better known than any of the other composers featured in this issue of TEMPO and, as I have been putting the issue together, I have been pondering the relationship between the music to which TEMPO's coverage is devoted and conventional ideas about what is noteworthy. Why is this music not better known? Does it matter that what TEMPO readers think of as mainstream music is regarded as wilfully obscure by most of the rest of the population?

There are lots of answers to those questions but although some of them may, as Ross suggests, make us think about the changing status of composers, none of them need depress us about the state of new music. Societies change and we live in a world where the available attention for any but the most spectacular cultural events is always divided. The production of art has proliferated, been democratised, and audiences have fragmented, only occasionally coalescing. So in this issue of TEMPO, readers will find the quite famous Adams alongside Martin Arnold, a composer little known outside the Canadian new music scene, itself a musical territory too little known, in spite of my predecessor Bob Gilmore's podcast 'Canada - the music of Generation X', part of his Tentative Affinities series (www.podcastchart. $\mathrm{com} /$ podcasts / tentative-affinities/ episodes/ canada-the-music-of-generat ion-x). Elsewhere an article that subjects a work by Helmut Lachenmann to detailed examination is a few pages away from a much more general consideration of the nature of musical discourse in recent music and just a few more pages away from a consideration of how a particular set of compositional ideologies have played out in the reception of British orchestral music.

Within the world of new music these articles may seem to represent a wildly diffuse set of topics - post-minimalism, complexity, musique concrète instrumentale, to name just the ones with readymade labels - but I would argue that the gap in public familiarity from Adams to Arnold, Lachenmann to Steen-Andersen, Benjamin to Hayden, is far narrower than that between any of them and Adele or Lady Gaga. Perhaps it might be useful to be less preoccupied 
by sectarian differences within new music and to observe instead how, from a distance, differences can merge?

Or perhaps not, because art does thrive on difference. The version of mainstream inhabited by Adams is a long way from that of Adele but it is still a sort of mainstream, a place Adams reached by eliminating difference, carefully paring away the radical elements from the various components of his musical style. If one is searching for innovative, exciting art it makes more sense to look at the margins than the mainstream, to go to concerts in Peckham Asylum in South London or Woodend Barn in Banchory rather than to the Barbican, to buy a ticket to hear Distractfold rather than the London Sinfonietta.

The more marginal the better, perhaps, and one of the paradoxes of late-capitalism is that the hollowing out of the centres of world cities has created cities full of marginal spaces. Nowhere in Europe is this more the case than in London, a city in which mainstream music organisations want to build yet another orchestral concert hall in spite of the fact that the city's most dynamic musical life is flourishing in alternative spaces, and in an unapologetically London-centred review section we celebrate that teeming, marginal life. Rather more apologetically I should also note that the featured composers in this issue are exclusively male; this does not represent editorial policy but is probably a topic for a future editorial. 